\title{
Patient-centered professionalism
}

This article was published in the following Dove Press journal:

Patient Intelligence

2 March 2012

Number of times this article has been viewed

\section{Hayley A Hutchings \\ Frances Rapport}

College of Medicine, Swansea University, Swansea, Wales, United Kingdom
Correspondence: Hayley A Hutchings College of Medicine, Swansea University, Singleton Park, Swansea, Wales, United Kingdom. SA2 8PP

Tel +44 1792513412

Fax +44 I792 5I 3423

Email h.a.hutchings@swansea.ac.uk
Introduction: Although the concept of patient-centered professionalism has been defined in the literature and adopted to some extent by key health care regulatory bodies, there has been little research that has identified what the concept means to professionals and patients.

Aim: The purpose of this paper is to identify the key concepts of patient-centered professionalism as identified in the literature and to discuss these within the context of existing research across a variety of health care settings.

Findings: Key documents have been identified from within nursing, medicine, and pharmacy, which outline what is expected of professionals within these professional groups according to their working practices. Although not defined as patient-centered professionalism, the principles outlined in these documents mirror the definitions of patient-centered professional care defined by Irvine and the Picker Institute and are remarkably similar across the three professions. While patients are identified as being at the heart of health care and professional working practice, research within the fields of community nursing and community pharmacy suggests that patient and professional views diverge as regards what is important, according to different group agendas. In addition, the delivery of patient-centered professional care is often difficult to achieve, due to numerous challenges to the provision of patient-centric care.

Conclusion: According to the literature, patient-centered professionalism means putting the patient at the heart of care delivery and working in partnership with the patient to ensure patients are well informed and their care choices are respected. However, limited research has examined what the concept means to patients and health care professionals working with patients and how this fits with literature definitions. Further work is needed to identify aspects of the concept as regards the importance placed on patient-centered professionalism and a mechanism is required for dissemination and integration of the findings to key monitoring and regulatory bodies. Major aspects of the concept, once identified within the various health care arenas, should be incorporated into heath care professional curricula and continued professional development.

Keywords: patient-centered professionalism, health care professionals, patients, public

\section{Introduction}

The concept of patient-centered professionalism has been explored to some extent within the medical literature, but there has been little research that has examined the notion within other health care arenas. Individual aspects of the concepts "patient-centeredness" and "professionalism" have been examined widely across medicine, nursing, and other health professions, but what this means as a joined-up notion has received less attention. 
Irvine, in a series of articles on patient-centered professionalism has said: "Patients want doctors who are competent, respectful, honest, and able to communicate with them." This is patient-centered professionalism. ${ }^{1} \mathrm{He}$ has outlined how these features should form the basis of good medical practice and how they should be embedded within the practice of doctors and regulated by the United Kingdom (UK) General Medical Council (GMC), in partnerships between the public and doctors. ${ }^{2}$ The key features of patient-centered professionalism as outlined by Irvine are identified in Table $1 .^{2}$

Further research conducted between 2004 and 2007 by the Picker Institute examined the nature of patient-centered professionalism. The research identified the core principles of patient-centered professionalism in the United States (US), Canada, and the $\mathrm{UK}^{3,4}$ and what this means to patients and professionals (see Table 2).

The concept, as described by Irvine ${ }^{2,5}$ and the Picker Institute $^{3,4}$ highlights the importance of a relationship between the patient and their practitioner and how the patient should be involved in treatment choices after being provided with adequate information. Irvine argues that from the professional perspective, patient-centered professionalism needs embedding within professional education and should be regulated through the appropriate authorities. ${ }^{2}$

The regulatory bodies within UK nursing, pharmacy, and medicine all place the patient at the heart of their professions and document what is expected professionally in the provision of care to the patient. Within medicine, the GMC in the UK sought to explicitly change from a doctor-centered approach to a patient-centered professional approach (following major reform in the early 2000 's). This change was initiated following high-profile cases of professional misconduct within the medical profession (The "Bristol Affair" in 1996 and the "Harold Shipman Inquiry" in 1999). The changes were intended to put the patient first and to facilitate both public and doctors' understanding of what constitutes good medical practice. ${ }^{5,6}$ Irvine $^{7}$ suggests that good medical

Table I Key features of patient-centered professionalism in UK medical practice outlined by Irvine in 2004 in his recommendations for medical standards and validation ${ }^{2}$

- Starts with patient autonomy

- Patients and public as partners

- Based on the values and standards agreed by the public and the medical profession

- Embedded in medical education

- Guaranteed through licensure and certification, and contracts of employment
Table 2 Core features of patient-centered professionalism identified from work carried out within the UK, US, and Canada by the Picker Institute to examine what this concept means $\mathrm{s}^{3,4}$

- People have the right to decide whether and when to consult a health service, and which one to consult

- Patients should be free to decide which treatment they want out of a range of treatments available for their conditions, or to refuse any treatment, or to cede the decision about treatment to someone else

- However, all decisions about treatment of an individual patient must be based on scientific knowledge and concern for equity, as well as on what the patient prefers

- In order for patients to make choices about their treatment, doctors and other health professionals should:

- present all relevant and available options and their implications

- get to know patients' own experience of the condition/illness and their preferences and values

- take these into consideration in presenting the options

- accept the decision-making role if the patient wishes the choice to be made by the professional

practice may be best achieved by professional regulation based on explicitly patient-centered professional standards embedded in medical education, registration and licensure, specialist certification, and doctors' contracts. Within UK nursing, the Nursing and Midwifery Council (NMC) have already adopted this approach, with evidence of patientcentered professionalism being embedded within their recent standards for reregistration nursing education. ${ }^{8}$

The Royal College of Nursing (RCN), NMC and International Council of Nurses (ICN) have laid down detailed and clear principles regarding what is expected of the nursing professions, which has been the basis for the definition of nursing, the code of ethics for nurses, and the standards of conduct, performance and ethics for nurses and midwives..$^{9-11}$ Patient-centered care is at the heart of the RCN definition of nursing and detailed standards regarding nursing professional conduct in relation to their practice with patients are provided by the RCN and the NMC. Similarly, the UK's Code of Ethics for Pharmacists and Pharmacy Technicians emphasizes detailed and clear principles regarding what is expected of these professionals ${ }^{12}$ and has been used as a basis for the production of a series of professional standards and guidance documents that expand upon the principles for specific areas of practice or professional activities.

Table 3 documents the key aspects outlined by the UK GMC, the Royal Pharmaceutical Society (RPS), the RCN, and the $\mathrm{NMC}^{5,9,11,12}$ as to what is required of doctors, pharmacists, and nurses. There are striking similarities between the three professions in terms of how they expect the professional to conduct her/himself, how the professional should treat the patient, how the professional should work with other 


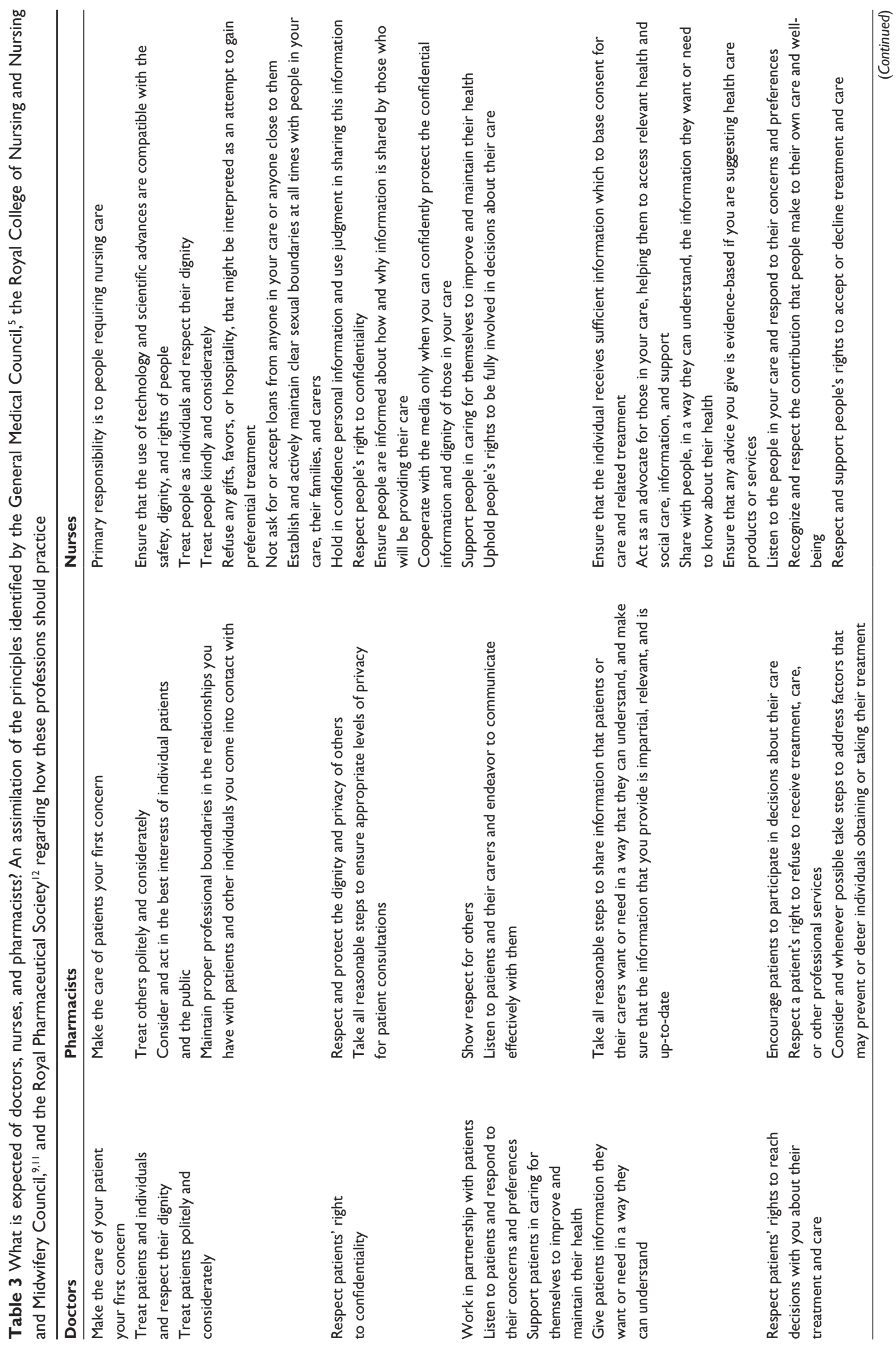



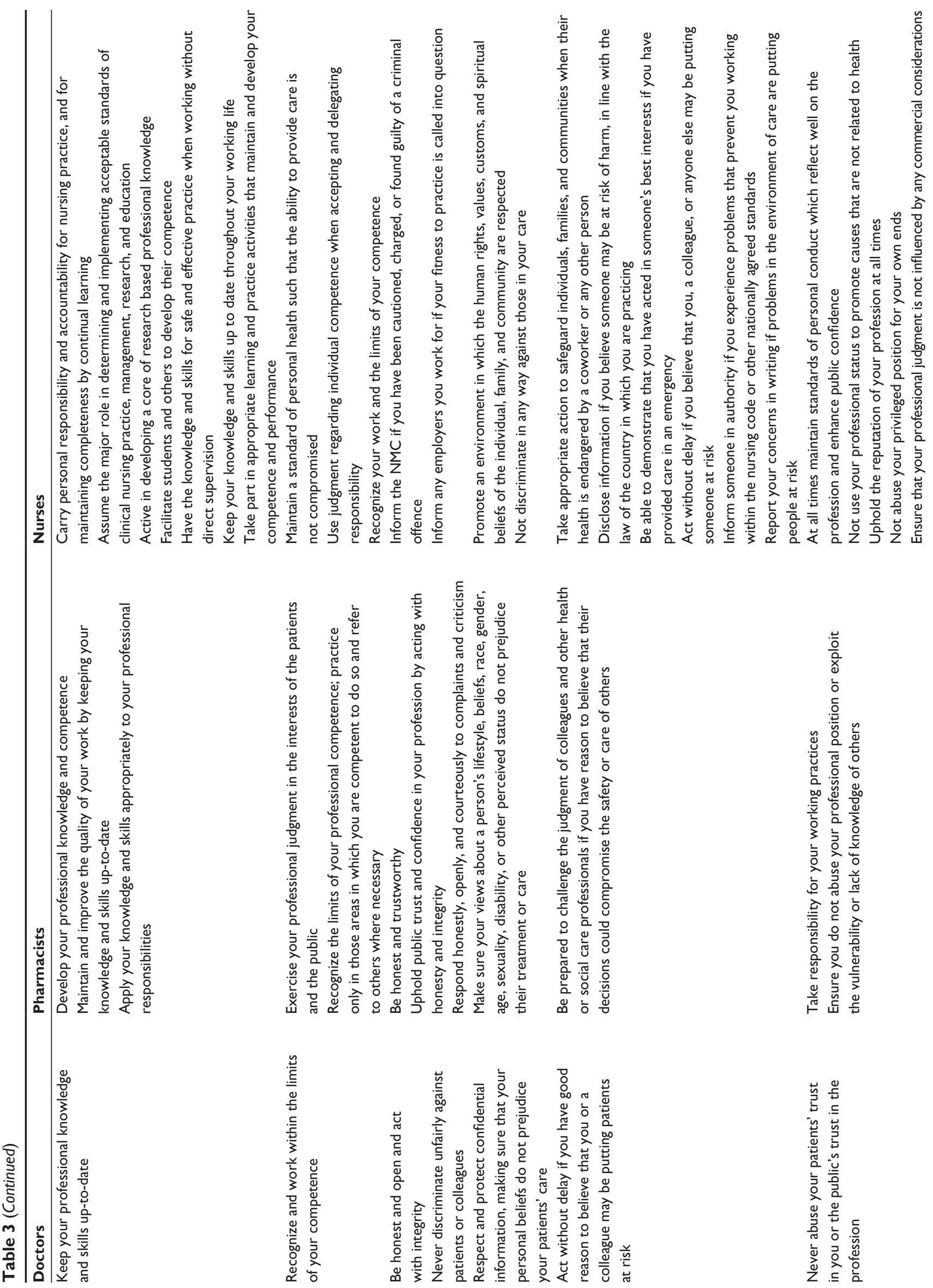

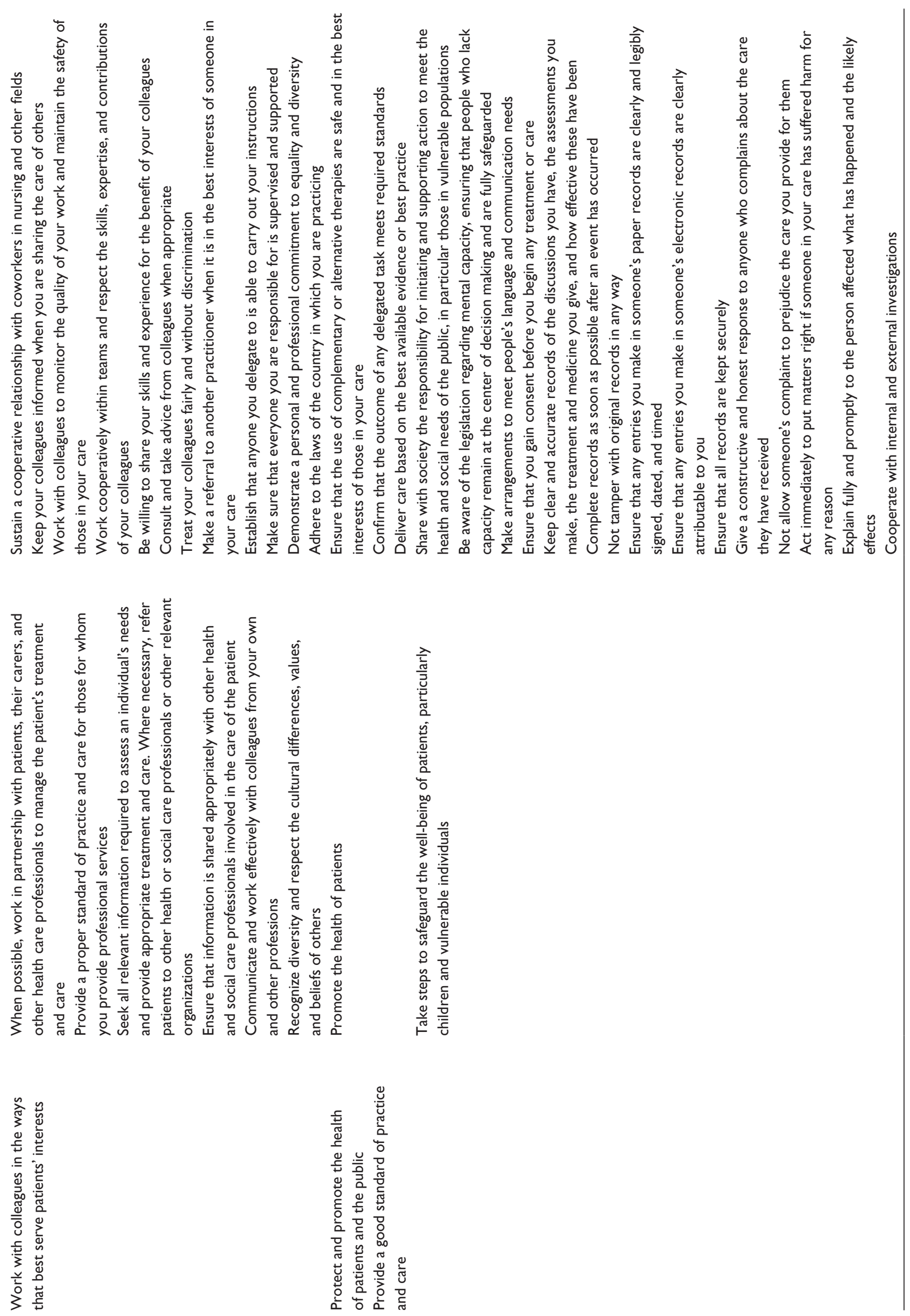
professionals, how confidentiality should be maintained, and how the reputation of the profession should be upheld. The patient is always the main focus, with every aspect of their professional conduct underpinned by the idea of the patientcentered care approach.

\section{What does patient-centered professionalism mean to patients?}

Although many health professions have recognized that patient-centered care and professionalism should be at the core of how their professions practice, there has been limited health services research that has examined what the concept of patient-centered professionalism means to professionals, stakeholders, patients, and the public, and whether there is consensus regarding what this means across these different groups. In order to deliver the best care to the patient, due consideration should be given to what patients think is important in the delivery of care and the treatment they receive, which should in turn have an impact on the organization and delivery of services. In addition, although standards and codes have been developed by the various professional bodies regarding how patients should be treated, whether these practices are being implemented in the delivery of care is not apparent.

In a study by Wiggins et al, which examined what patients and the public perceived as the characteristics of doctors most closely aligned to patient-centered professionalism, patients and the public concluded that communication skills and compassion were more important than social behaviors, such as appearance and acknowledgment of family members. ${ }^{13}$

Recent work in the UK employing mixed-methods consultation workshops with professionals, stakeholders, patients, and the public from 2008 to 2010 aimed to contextualize what patient-centered professionalism meant to these groups, and by employing novel methodology attempted to gain consensus regarding the concept and its import within a mixed population. ${ }^{14-17}$ Within the UK community pharmacy setting, for example, what was regarded as the most important aspect of patient-centered professionalism to patients and members of the public, was getting the correct prescription dispensed. They felt that a lack of patient-centered professionalism would be evidenced by mistakes in the administration and delivery of medicines (see Table 4). For patients and the public, the social aspects of the pharmacy-patient interaction were regarded as less important than an efficient service and dispensing facility. ${ }^{14}$ For professionals, on the other hand, the important aspects of good patient-centered professionalism related primarily to the patient interaction.
Table 4 What does patient-centered professionalism mean for patients and the public? Examples of good practice and challenges to patient-centered professionalism. Case study examples taken from studies within community pharmacy and community nursing ${ }^{14,17}$

\begin{tabular}{|c|c|}
\hline $\begin{array}{l}\text { Examples of good patient- } \\
\text { centered professionalism }\end{array}$ & $\begin{array}{l}\text { Examples of challenges to patient- } \\
\text { centered professionalism }\end{array}$ \\
\hline \multicolumn{2}{|c|}{ Members of public: community pharmacy } \\
\hline Correct prescriptions & $\begin{array}{l}\text { Mistakes in administering/delivering } \\
\text { medicines }\end{array}$ \\
\hline Quick, efficient services & Long waits for prescriptions \\
\hline Accessible & Too busy, problems with multi-tasking \\
\hline Dedicated dispensary & Lack of confidentiality \\
\hline Good hygiene & Lack of patient history \\
\hline List of services on offer & Stress related to heavy workloads \\
\hline Personable & Indistinct environment \\
\hline $\begin{array}{l}\text { Work with general } \\
\text { practitioner }\end{array}$ & Lack of clarity of roles and services \\
\hline Relationship of equals & Too commercial \\
\hline Taking on new roles & Captive pricing \\
\hline \multicolumn{2}{|c|}{ Members of public: community nursing } \\
\hline Putting the patient first & Inadequate training and clinical skills \\
\hline Using appropriate skills & Lack of respect for patients \\
\hline Time management & Poor communication skills \\
\hline Good communication skills & Inappropriate interpersonal skills \\
\hline Flexibility and adaptability & Unclear understanding of role \\
\hline Respect & Poor interprofessional relationships \\
\hline Friendly and approachable & Inconsistency of nursing care \\
\hline $\begin{array}{l}\text { Acquiring appropriate skills } \\
\text { and knowledge (training) }\end{array}$ & Lack of facilities and space \\
\hline \multicolumn{2}{|l|}{ Continuity of care } \\
\hline \multicolumn{2}{|l|}{ Accessibility } \\
\hline Interprofessional relationships & \\
\hline
\end{tabular}

So while the patients wanted a quick and efficient dispensing service, where their needs and expectations came first, pharmacists found that pressing patient demands had a negative impact on their ability to deliver a patient-centered and professional service. This mismatch between what patients and public and professional groups regard as being important to patient-centered professionalism could reflect the historical perception by the patient that pharmacists are prescribers of medicine without recognizing the recent increased involvement of UK pharmacists in carrying out patient consultations as well as dispensing. Many of the important aspects of the treatment of patients outlined by the RPS in their Code of Ethics for Pharmacists and Pharmacy Technicians were highlighted in this study which might allude to, as in the medical profession, a change in focus to more patient-centric care. ${ }^{12}$

Findings from the UK community nursing setting painted a different picture regarding what patients and the public saw as important in the delivery of patient-centered 
professional care. In this environment, patients and the public regarded the patient-nurse social interaction as the most important aspect that demonstrated good patient-centered professionalism (see Table 4). Unlike the findings from the community pharmacy setting, UK community nurses mirrored the perspective of the patient and public group, putting the patient first as the most important aspect of providing good patient-centered professional care. ${ }^{17}$ These results are in accordance with the RCN document which defines nursing 9 as an area where patient need should always be put before professional expectation. In comparison with patients' views of the pharmacist, ${ }^{12}$ the UK community nursing research study emphasizes that patients' perceive the nurse-patient relationship as paramount and the main focus of treatment.

\section{What does patient-centered professionalism mean to health care professionals?}

In a mixed methods study, Maudsely et al explored what junior medical students' notions of being a "good doctor" were, and highlighted the necessity of such information being used in the development of medical curricula. The study cohort valued as important aspects of being a good doctor, being "compassionate, a patient-centered carer" and a "listening, informative communicator." These characteristics were rated more highly than being an "exemplary, responsible professional." 18

Another recent study with young pharmacists has examined the role of the pharmacy professional. Among those taking part in the research, trust was perceived as key to professionalism as well as delivering care that was patientcentered. A critical attribute associated with trust was being able to establish credibility with patients and with other health care professionals, whether it was through having the knowledge to provide medical expertise, the integrity to act in the patient's best interest, and the confidence to interact with both the pharmacy team and patients in an appropriate manner rather than through relatively superficial qualities such as dressing appropriately. ${ }^{19}$

Our own work, within the community pharmacy and community nursing settings, served to clarify what patientcentered professionalism meant to professionals working within these fields and what they regarded as the most important aspects, as well as the barriers, to the delivery of patient-centered professional care. ${ }^{14,17}$ Within both of these studies the key aspects of the RPS's code of conduct, the NMC's standards of conduct, performance and ethics for nurses and midwives, and the GMC's code of ethics were evidenced throughout the consultation workshops with professionals. However, there were considerable constraints identified which were perceived to have a marked negative impact on nurses' and pharmacists' ability to deliver patientcentered professional care (see Table 5).

Although managing the patient was regarded as the most important aspect of the professional role and was the focus for the way that care was delivered in both professions, constraints to the delivery of patient-centered professional care were identified. ${ }^{14,17}$ Within community pharmacy, the pressures of the business environment and the requirement to meet targets and work quotas were factors that strongly affected care delivery. In addition, both the pharmacy and nursing professions were affected by limited resources (time and equipment), poor environment, and the impact of short-termism (see Table 5). This accords with barriers to patient-centered care highlighted within the nursing literature which included a lack of a clear definition of patient-centered care, an inadequate educational emphasis on patient-centered care, a lack of coordination of care packages, a shortage of staff, and an absence of good teaching models for patient-centered care. ${ }^{20-23}$ The principles outlined in the RPS's Code of Ethics for Pharmacists and Pharmacy Technicians ${ }^{12}$ and the RCN's definition of nursing ${ }^{9}$ were very much in evidence in our professional groups' work, but professionals' ability to behave in the manner outlined by these documents was often seen to be of great challenge to them, due to significant barriers, such as governmentdriven workload targets, to the delivery of high-quality patient-centered professional care.

\section{How can patient-centered professionalism be incorporated into the everyday practice of health care professionals?}

Within the context of medical patient-centered professionalism, Irvine stated that "The starting point is for the medical profession and the public together to put patient-centered professionalism at the heart of their vision for the future of medical care" 24 and that "To make patient-centered professionalism work we need leaders in the profession, who have the will to drive the movement forward and the strength of ethical purpose to see that the public interest always comes first." 24

The medical, pharmacy, and nursing professions have all identified the importance of the patient being at the heart of the delivery of care. In line with this, there is an identified need to include patient-centered professionalism within the education and curriculum-building aspects of all medical and 


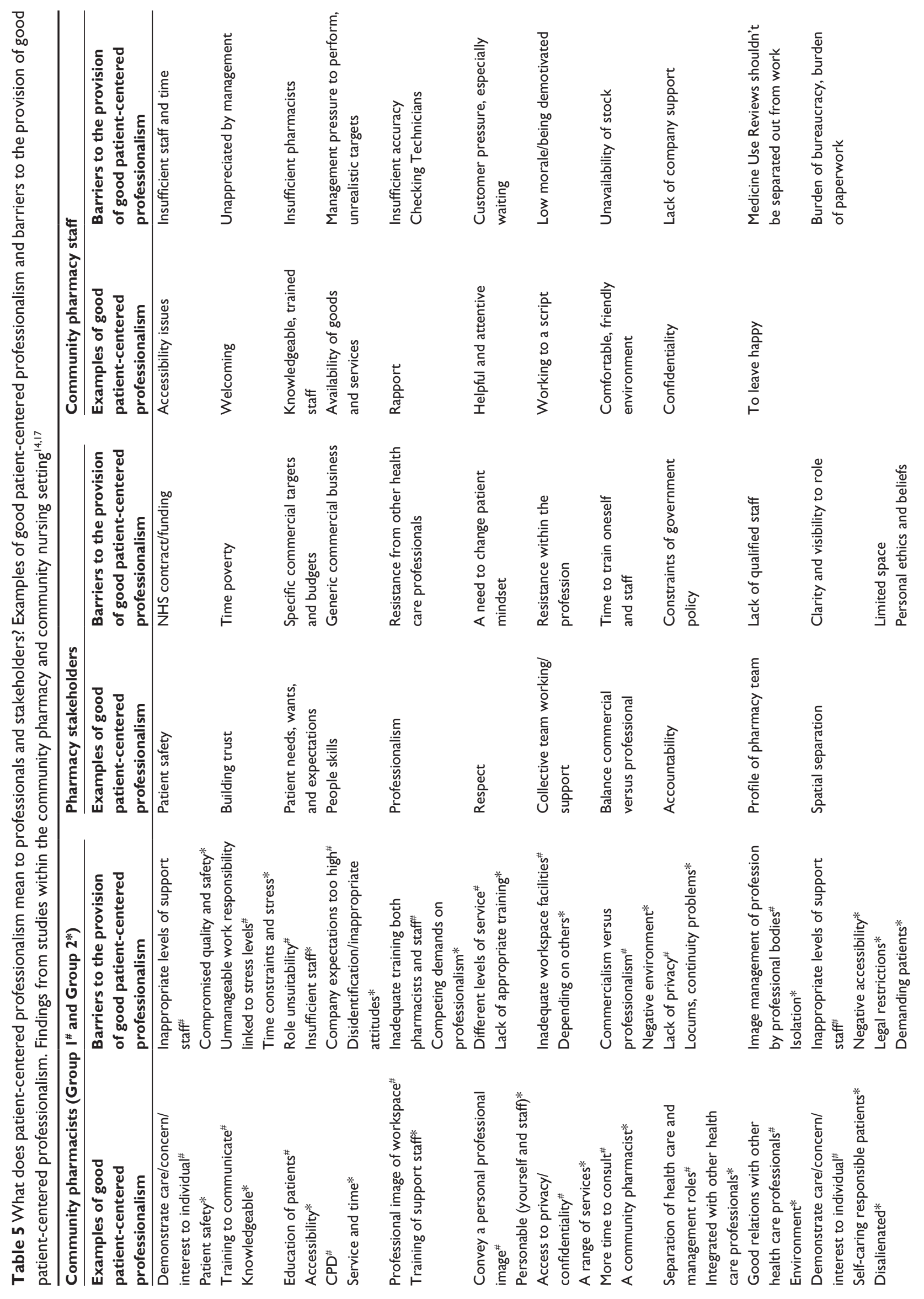



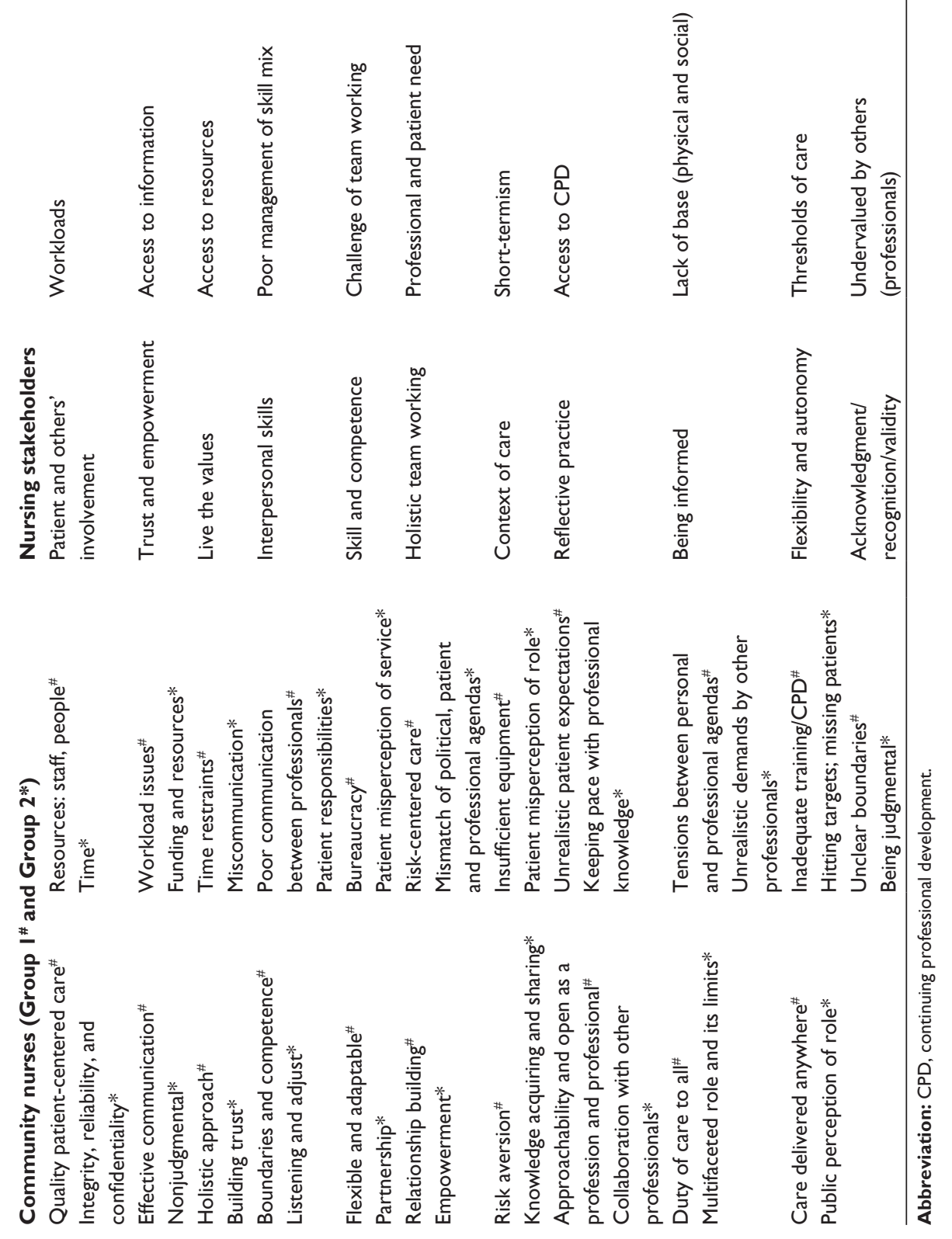
allied professions' educational work and to include ongoing training and development of these concepts alongside regulation and monitoring of the professionals involved. As patients are increasingly able to access more information regarding their conditions via the media (such as the Internet), they have increased expectations in terms of the quality of the care they receive and the range of choices available to them.

One of the major principles of patient-centered professionalism outlined by the Picker Institute was to provide sufficient information to the patient to allow them to make informed choices and for the professions to respect these choices. ${ }^{3,4}$ This partnership between the patient and the profession can only serve to improve the care and outcomes of the patients. However, the provision of patient-centered professional care by health professionals is becoming increasingly challenging in today's economic climate. Clearly there are complex practical, institutional, and professional issues to be resolved regarding the working partnership between patients and professionals. Further work is needed to explore these issues in order to identify how these partnerships could work and how easily these partnerships could be implemented.

In our recent work within community pharmacy and community nursing many conflicts are identified as having an impact on the provision of patient-centered professional care. Issues such as hitting targets (governmental, health services, or company targets), economic pressures resulting in reduced workforces and resources, inadequate work environments, and time constraints affect the provision of high-quality patient-centered and timely care provision.

\section{Future directions}

A limitation of this paper is its attempt to contextualize findings from recent research within the fields of community nursing and pharmacy in relation to published standards of patient-centered care and professionalism. Further research is now needed to identify the important aspects of patientcentered professionalism both within and across different health care professions and to determine how these fit with definitions highlighted within the medical and health care professions..$^{2-4}$ Such work should include both patients and professionals to obtain consensus regarding the most important positive aspects and the challenges to the provision of patient-centered professional care. How these fit with the core principles outlined by the Picker Institute need to be identified and fed back to organizations such as the RCN, GMC, and RCP in a UK context and others internationally, to ensure the appropriate delivery, regulation, and sustainability of patient-centered professional care. Irvine recognized the importance of ongoing regulation in the provision of patient-centered care and that this should be incorporated within curriculum development for health professionals and ongoing professional development. ${ }^{2}$ There should be recognized standards of patient-centered professional care and defined mechanisms for monitoring these. Within health services research, the benefits of including service users (patients and carers) and members of the public for a wider, more generic view on all the issues is clear. The inclusion of service users should also be considered within organizations that monitor and regulate the provision of patient-centered professional care. In order to enable the delivery of patientcentered professional care, due consideration should also be given regarding the most appropriate resources and the impact of target-driven working practices in order to ensure the highest standards of working practice.

\section{Conclusion}

It is important to consider the views of both patients and professionals in order to get a balanced opinion regarding what patient-centered professionalism means, and to gain a greater understanding of why patient-centered professionalism is an important feature of care provision to patients and professionals. The published literature within various health care fields was examined in order to define what the concept of patient-centered professionalism meant. By drawing on findings from community pharmacy and community nursing, an attempt was made to look at the issue across a range of population groups, to determine whether consensus exists regarding the concept's meaning and importance. Our findings from these two discrete studies indicated that patients, the public, and professionals have mixed views.

Patient-centered professionalism has been defined in the literature as putting the patient at the heart of care delivery and working in partnership with the patient and the wider public, to ensure patients are well informed and care choices are respected. The concepts of patient-centered professionalism, although not defined as such, are evident within key medicine, pharmacy, and nursing documents. However, there has been limited research that has directly examined what the notion means to patients and health care professionals and how this fits with the definition of the concept. Further work is needed to identify a mechanism for dissemination and integration of the findings to key monitoring and regulatory bodies. The key aspects of patient-centered professional care identified within the various health care arenas should be incorporated into heath care professional curricula and continued professional development and regularly updated. 
Regulatory authorities need to consider the impact of target driven working practices and the economic climate on health care professionals' ability to deliver patient-centered professional care. Further research is necessary across the spectrum of health care professions to determine how patients, the public, and professionals define the concept of patient-centered professionalism and whether a consensus can been gained regarding the relative importance of its constituent parts. Additional work also needs to be carried out to determine whether the practice of patient-centered professionalism is truly being integrated into patient care, service delivery, and organization.

\section{Disclosure}

The authors report no conflicts of interest in this work.

\section{References}

1. Irvine DH. Time for hard decisions on patient-centred professionalism. Med J Aust. 2004;181(5):271-274.

2. Irvine D. Standards and revalidation or recertification. Ann Acad Med Singapore. 2004;33(6):715-719.

3. Picker Institute Europe. Patient-centred professionalism: Defining the public's expectations of doctors. May 2008. Available from: http://www. pickereurope.org/Filestore/PIE_reports/project_reports/PCPfinalreportPIIMay2008.pdf. Accessed on.

4. Askham J, Chisholm A. Patient-centred medical professionalism: Towards an agenda for research and action. Mar 2006. Available from: http://www.pickereurope.org/Filestore/PIE_reports/PCP/pcpconceptsreport-PDF.pdf. Accessed on.

5. General Medical Council. Good Medical Practice. London, UK: General Medical Council; 1995.

6. Donaldson L. Good Doctors, Safer Patients: Proposals to Strengthen the System to Assure and Improve the Performance of Doctors and to Protect the Safety of Patients. London: Department of Health; 2006.

7. Irvine DH. Everyone is entitled to a good doctor. Med J Aust 2007;186(5):256-261.

8. Standards for pre-registration nursing education (2010). Nursing and Midwifery Council Web site. Available from: http://standards.nmc-uk. org/Pages/Welcome.aspx. Accessed January 27, 2012.

9. Royal College of Nursing. Defining Nursing. Apr 2003. Available from: http://www.rcn.org.uk/_data/assets/pdf_file/0008/78569/001998.pdf. Accessed on.
10. International Council of Nurses. The ICN Code of Ethics for Nurses. Available from: http://www.icn.ch/images/stories/documents/about/ icncode_english.pdf. Accessed on.

11. Nursing and Midwifery Council. The code: Standards of conduct, performance and ethics for nurses and midwives. Published May 2008.

12. Royal Pharmaceutical Society of Great Britain. Code of Ethics for Pharmacists and Pharmacy Technicians. London: Royal Pharmaceutical Society, 2007.

13. Wiggins MN, Coker K, Hicks EK. Patient perceptions of professionalism: implications for residency education. Med Educ. 2009; 43(1):28-33.

14. Hutchings HA, Rapport FL, Wright S, Doel MA, Wainwright P. Obtaining consensus regarding patient-centred professionalism in community pharmacy: nominal group work activity with professionals, stakeholders and members of the public. Int J Pharm Pract. 2010;18(3): 149-158.

15. Rapport F, Doel MA, Hutchings HA, et al. Through the looking glass: public and professional perspectives on patient-centred professionalism in modern-day pharmacy. Forum Qual Soc Res. 2010;11(1):7.

16. Rapport F, Doel MA, Hutchings HA, Wright S, Wainwright P, John DN, et al. Eleven themes of patient-centred professionalism in community pharmacy: innovative approaches to consulting. Int $J$ Pharm Pract. 2010;18(5):260-268.

17. Hutchings HA, Rapport F, Doel MA, Wright S, Jones A. Obtaining consensus regarding patient-centred professionalism in community nursing: nominal group work activity with professionals and the public. Int J Pharm Pract. 2010;18(3):149-158.

18. Maudsley G, Williams EMI, Taylor DCM. Junior medical students' notions of a "good doctor" and related expectations: a mixed methods study. Med Educ. 2007;41(5):476-486.

19. Willis S, Schafheutle EI, Elvey R, Lewis P, Harrison S, Hassell K. Can patient-centred professionalism be engendered in young pharmacists? Pharm J. 2011;287:203-204.

20. Pelzang R. Time to learn: understanding patient-centred care. Br J Nurs. 2010;19(14):912-917.

21. Pelzang R, Wood B, Black S. Nurses' understanding of patient-centred care in Bhutan. Br J Nurs. 2010;19(3):186-193.

22. McCormack B, Dewing J, McCance T. Developing person-centred care: addressing contextual challenges through practice development Online J Issues Nurs. 2011;16(2):3.

23. Bolster D, Manias E. Person-centred interactions between nurses and patients during medication activities in an acute hospital setting: qualitative observation and interview study. Int J Nurs Stud. 2010;47(2): 154-165.

24. Irvine D. 17th Gordon Arthur Ransome oration: patient-centred professionalism. Ann Acad Med Singapore. 2004;33(6):680-685.
Patient Intelligence

\section{Publish your work in this journal}

Patient Intelligence is an international, peer-reviewed, open access journal that characterizes and measures the central role of patient behavior and intention in optimizing healthcare management in all areas of disease and complaint types. An improved understanding of patient intelligence coupled with predictive analysis helps an organization contribute more effectively to achieving better outcomes

Submit your manuscript here: http://www.dovepress.com/patient-intelligence-journal

\section{Dovepress}

The journal is characterized by the rapid reporting of reviews, original research, methodologies, analytics, modeling, clinical studies and patient surveys across all disease areas. The manuscript management system is completely online and includes a very quick and fair peer-review system. Visit http://www.dovepress.com/ testimonials.php to read real quotes from published authors. 